The Free Internet

Journal

for Organic Chemistry

Archive for

Organic Chemistry

Arkivoc 2018, vii, 442-448

\title{
Concise asymmetric syntheses of (S)-ethyl 4-methyloctanoate and its acid: aggregation pheromones of rhinoceros beetles of the genus Oryctes
}

\author{
Rachana Pandey and Ranjana Prakash* \\ School of Chemistry and Biochemistry, Thapar Institute of Engineering and Technology, Patiala 147 001, India \\ Email: rprakash@thapar.edu
}

Received 01-09-2018

Accepted $10-15-2018$

Published on line 12-07-2018

\section{Abstract}

A concise stereoselective approach to the asymmetric syntheses of (S)-ethyl 4-methyloctanoate and its acid, main aggregation pheromones of the genus Oryctes and an important fragrance compounds, is described. The synthesis utilizes the organocatalyzed MacMillan's cross aldol reaction as key step. The synthetic approach outlined permits synthesis of a variety of enantiopure branched methyl unsaturated and saturated fatty acids.

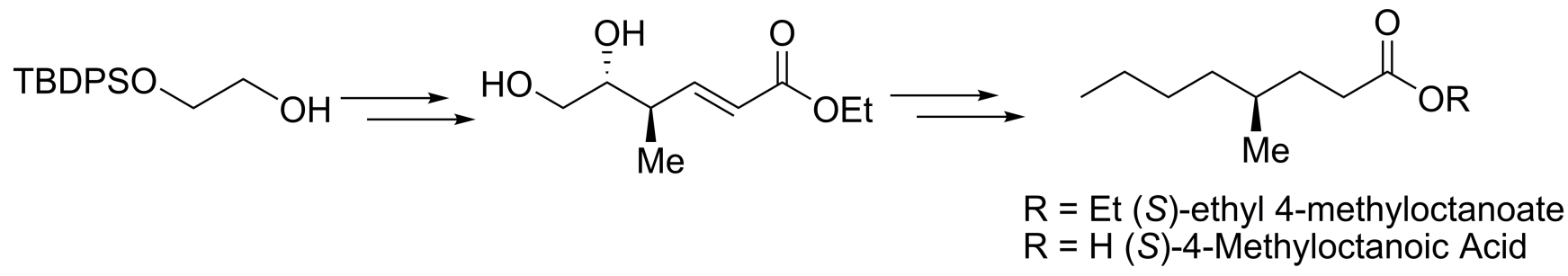

Keywords: Rhinoceros Beetle, Aggregation Pheromone, MacMillan's cross Aldol reaction, Wittig olefination, Fragrance 


\section{Introduction}

Rhinoceros beetles and rhynchophorus weevil of the genus Oryctes and Rhynchophorus, respectively, are the two most significant destructive pests of commercial coconut (Cocos nucifera), date and oil palm plantations in Africa, South-east Asia and Indian islands. ${ }^{1-3}$ Rhinoceros beetle attacks kill adult palms, provide entry point for palm weevils, destructive insects and lethal diseases, reduce photosynthetically and damage inflorescences and thereby, deteriorating revenue of coconuts and date and oil palms production. ${ }^{4}$ The ethyl 4methyloctanoate (1) and its acid derivative $\mathbf{2}$ are the two most important aggregation pheromone components emitted by male rhinoceros beetles. ${ }^{5}$ The 4-methyl-5-nonanol (3) and 4-methyl-5-nonanone (4) are recognized as Rhynchophorus ferrugineus Oliv. aggregation pheromones (Figure 1). ${ }^{6-9}$ The 4methyloctanoic acid $\mathbf{2}$ has been also identified as a main fragrance compound of various foods such as Italian cheese, ${ }^{10}$ Turkish tobacco, ${ }^{11}$ and within perinephric fats of a variety of red meat species. ${ }^{12}$

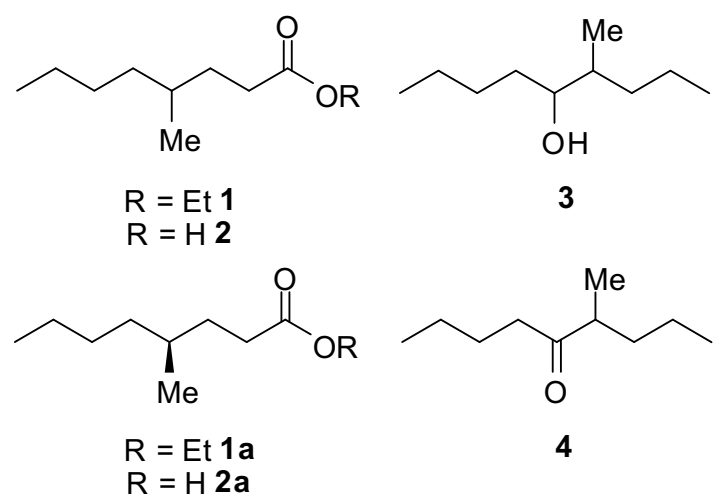

Figure 1. Structure of aggregation pheromones of rhinoceros beetles $(\mathbf{1 , 2})$ and rhynchophorus weevils $(\mathbf{3}, \mathbf{4})$.

Various methods for the racemic synthesis of ethyl 4-methyloctanoate (1) and its acid derivative $\mathbf{2}$ have been documented in the literature.,13-17 Most of the asymmetric syntheses for $(R)$ - and $(S)$-ethyl 4methyloctanoate (1) and its acid $\mathbf{2}$ described employed either use of chromatographic diastereomeric separation of phenylethylamides ${ }^{18}$ or phenylglycinol amides, ${ }^{19}$ chiral citronellol as starting material or enzymatic resolution. ${ }^{20-22}$ More recently, Guerrero and co-worker reported the asymmetric synthesis of $(R)$ and (S)-4-methyloctanoic acid (2) via chirality induction through Myers alkylation reaction as key step. ${ }^{23}$ Herein, we are reporting a simple synthetic approach to the ethyl 4-methyloctanoate (1) and its acid $\mathbf{2}$ and further its application to the asymmetric syntheses (S)-ethyl 4-methyloctanoate (1a) and its acid $\mathbf{2 a}$ from monosilylated ethylene glycol as a starting material employing organocatalyzed MacMillan's cross aldol reaction and Wittig olefination as key steps.

\section{Results and Discussion}

Our retrosynthetic analysis to the synthesis of (S)-ethyl 4-methyloctanoate (1a) and its acid $\mathbf{2 a}$ is displayed in Scheme 1 . The $\alpha, \beta$-unsaturated ester derivative 6 was visualized as a synthetic intermediate from which ethyl 4-methyloctanoate (1) and its acid $\mathbf{2}$ could be synthesized via silyl ether deprotection, oxidative cleavage of diol, Wittig homologation and reduction following standard organic functional group transformations. The $\alpha, \beta-$ unsaturated ester derivative 6 envisaged from readily available monosilylated ethylene glycol derivative 7 via 
organocatalyzed MacMillan's cross aldol reaction of aldehyde derived from 7 with propionaldehyde and Wittig homologation reaction. The $(R)$ - and $(S)$ - configuration of the target compounds ethyl 4-methyloctanoate (1) and its acid $\mathbf{2}$ can be manipulated by simply changing organocatalyst under MacMillan's cross aldol conditions.

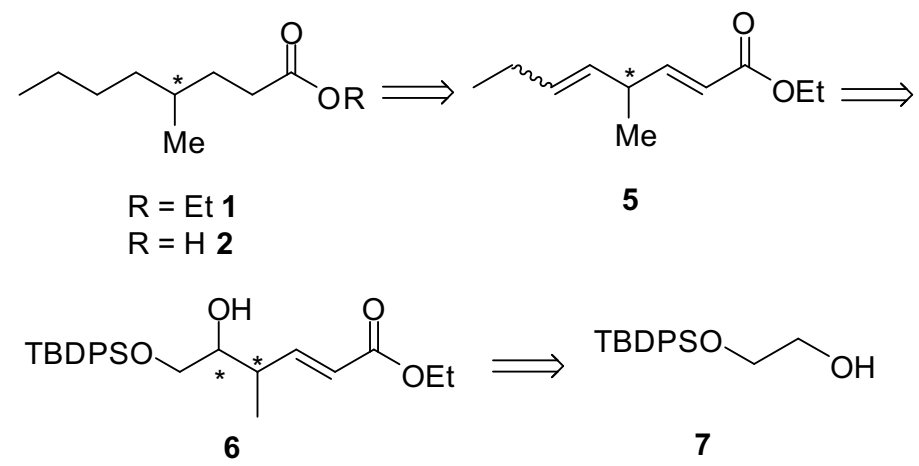

Scheme 1. Retrosynthetic approach to asymmetric syntheses of ethyl 4-methyloctanoate (1) and its corresponding ethyl ester $\mathbf{2}$.

Our approach for the asymmetric synthesis of $(S)$-ethyl 4-methyloctanoate (1a) and its acid $\mathbf{2 a}$ is depicted in Scheme 2. Syntheses of target compounds (S)-1a and (S)-2a began with readily available monosilylated ethylene glycol 7 which was subjected to a two-step sequence including Swern oxidation followed by Lproline catalyzed MacMillan's cross aldol reaction to afford the diastereomeric mixture of aldehyde $\mathbf{5}$ with $>99 \%$ ee (anti/syn 9:1) ${ }^{26}$ and subsequent 2C-Wittig olefination without separation with (ethoxycarbonylmethyl-ene)triphenylphosphorane furnished unsaturated ester 6a following a literature procedure. ${ }^{27-28}$

With olefin derivative $6 \mathbf{6}$ in hand, we then subjected it to silyl ether deprotection to get the diol intermediate 9. Pleasingly, the minor diastereomer was separated out during column chromatography purification. The $\mathrm{NaIO}_{4}$ mediated oxidative cleavage of terminal diol $\mathbf{9}$ followed by treatment of aldehyde intermediate with phosphonium salt (propyltriphenyl-phosphonium bromide) in presence of $n$-BuLi as a base furnished the olefin derivative 10. In view of the fact that the incipient olefin would be ultimately hydrogenated to get the target compound 1a we did not examine the olefin geometry of derivative $\mathbf{1 0}$. Accordingly, the olefin derivative 10 on hydrogenation at one atmospheric pressure in the presence of $10 \%$ $\mathrm{Pd}-\mathrm{C}$ furnished the target compound $(S)$-ethyl 4-methyloctanoate (1a) in 76\% yield (over three steps); $[\alpha]_{D}{ }^{25}$ +1.61 ( $c$ 1.0, $\mathrm{CHCl}_{3}$ ); $\left\{\right.$ lit. $^{4}[\alpha]_{\mathrm{D}}{ }^{20}+1.67$ (c 1.35, $\left.\left.\mathrm{CHCl}_{3}\right)\right\}$. Finally, saponification reaction of the (S)-ethyl 4methyloctanoate (1a) with $\mathrm{LiOH}$ in aqueous THF solvent at room temperature afforded the target compound (S)-4-methyloctanoic acid (2a) in 92\% Yield; $[\alpha]_{D}{ }^{25}+1.46$ (c 1.0, $\mathrm{CHCl}_{3}$ ); $\left\{\mathrm{lit}^{23}[\alpha]_{\mathrm{D}}{ }^{20}+1.5\right.$ (c 1.4, $\left.\left.\mathrm{CHCl}_{3}\right)\right\}$. The physical and spectroscopic data were in full agreement with those reported literature. 

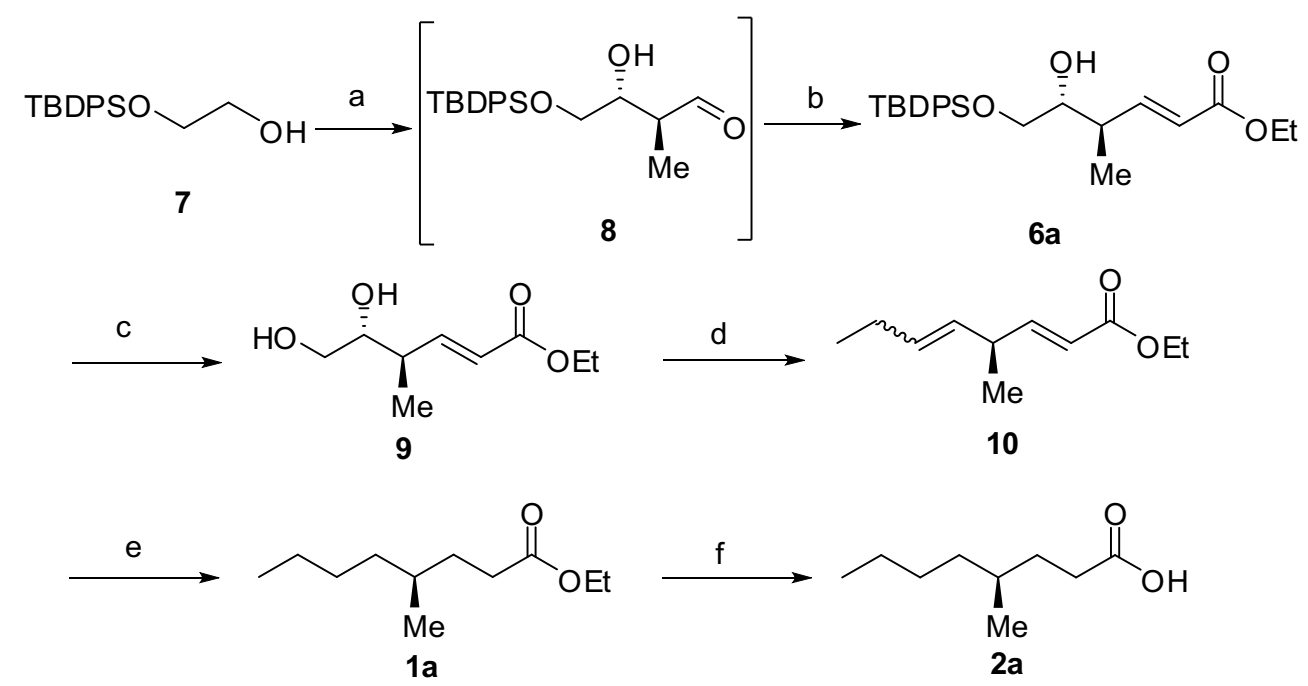

Scheme 2. Reagents and conditions: (a) i) $(\mathrm{COCl})_{2}, \mathrm{DMSO}, \mathrm{Et}_{3} \mathrm{~N}$, dry $\mathrm{CH}_{2} \mathrm{Cl}_{2},-78{ }^{\circ} \mathrm{C}$ to rt, $3 \mathrm{~h}$; ii) $\mathrm{C}_{3} \mathrm{H}_{6} \mathrm{O}, 10 \mathrm{~mol} \%$ L-Proline, dioxane, $4{ }^{\circ} \mathrm{C}, 48 \mathrm{~h}, 94 \%$ (over two steps); (b) Ph 3 PCHCOOEt, dry THF, rt, $24 \mathrm{~h}, 92 \%$; (c) TBAF, THF, rt, 4 h, 95\%; (d) i) $\mathrm{NaIO}_{4}$, THF: $\mathrm{H}_{2} \mathrm{O}(1: 1)$, rt, 20 min.; ii) propyltriphenylphosphonium bromide, $n$-BuLi, $\mathrm{THF},-78^{\circ} \mathrm{C}$ to rt, 3 h; (e) $\mathrm{H}_{2}, 10 \% \mathrm{Pd}-\mathrm{C}, \mathrm{MeOH}, \mathrm{rt}, 4 \mathrm{~h}, 76 \%$ (over three steps); (f) LiOH, THF: $\mathrm{H}_{2} \mathrm{O}$ (4:1), rt, 6h, $92 \%$.

\section{Conclusions}

In conclusion, we have developed a simple and flexible approach to the total syntheses of (S)-ethyl 4methyloctanoate (1a) and its acid $\mathbf{2 a}$ from readily available starting materials. The synthetic sequence demonstrates the application of organocatalyzed MacMillan's cross aldol reaction and Wittig olefination as the key steps. The synthetic approach described has significant potential for stereochemical variations and further extension to other stereoisomers and their analogues.

\section{Experimental Section}

Ethyl (4R,5R,E)-5,6-dihydroxy-4-methylhex-2-enoate (9). To a stirred solution of unsaturated ester $6 \mathbf{6 a}$ (1.4 g, $3.28 \mathrm{mmol})$ in dry THF $(10 \mathrm{~mL}) \operatorname{TBAF}(4.91 \mathrm{~mL}, 4.92 \mathrm{mmol})$ was added dropwise at room temperature. After stirring the reaction mixture at room temperature for $4 \mathrm{~h}$, the reaction mixture was diluted with water and ethyl acetate. The organic layer was washed with brine, dried over anhydrous $\mathrm{Na}_{2} \mathrm{SO}_{4}$ and the solvent was evaporated under reduced pressure. Silica gel column chromatography (hexane/EtOAc, 4:1) furnished olefin diol 9 (988 mg, 95\%) as a colorless liquid. $[\alpha]_{D}^{25}+9.56$ (c 1.0, $\left.\mathrm{CHCl}_{3}\right)$; IR $\left(\mathrm{CH}_{2} \mathrm{Cl}_{2}\right)$ v: 3425, 2957, 2926, 1720, 1478, 1268, $1220 \mathrm{~cm}^{-1} ;{ }^{1} \mathrm{H}$ NMR $\left(400 \mathrm{MHz} \mathrm{CDCl}_{3}\right) \delta: 6.97$ (dd, J 8.28, $\left.15.6 \mathrm{~Hz}, 1 \mathrm{H}\right), 5.87(\mathrm{~d}, J 14.68 \mathrm{~Hz}, 1 \mathrm{H}), 4.19$ (q, J 7.32, 14.2 Hz, 2H), 3.71-3.59 (m, 2H), 3.56-3.49 (m, 1H), 3.08 (brs, 2H), 2.54-2.45 (m, $1 \mathrm{H}), 1.29(\mathrm{t}, J 7.32$ $\mathrm{Hz}, 3 \mathrm{H}), 1.1$ (d, J $6.84 \mathrm{~Hz}, 3 \mathrm{H}) ;{ }^{13} \mathrm{C} \mathrm{NMR}\left(100 \mathrm{MHz}, \mathrm{CDCl}_{3}\right) \delta: 166.8,150.3,121.9,74.8,64.5,60.4,39.5,15.8$, 14.2. HRMS (ESI), $m / z$ calcd for $\mathrm{C}_{9} \mathrm{H}_{16} \mathrm{O}_{4} \mathrm{Na}[\mathrm{M}+\mathrm{Na}]^{+} 211.0941$; found 211.0952 .

Ethyl (S)-4-methyloctanoate (1a). To a stirred solution of $\mathrm{NalO}_{4}(226 \mathrm{~g}, 1.06 \mathrm{mmol})$ in $\mathrm{H}_{2} \mathrm{O}: \mathrm{THF}(1: 1,10 \mathrm{~mL})$ was added a suspension of olefin diol $9(100 \mathrm{mg}, 0.53 \mathrm{mmol})$ in THF $(3 \mathrm{~mL})$ and stirred for 20 min at room temperature. To the reaction mixture EtOAc and water were added, the aqueous layer was extracted with 
EtOAc ( $3 \times 15 \mathrm{~mL}$ ). The combined organic layer was washed with brine, dried over anhydrous $\mathrm{Na}_{2} \mathrm{SO}_{4}$, and concentrated in vacuo. The aldehyde intermediate obtained was used as such for next reaction without further purification.

To a suspension of propyltriphenylphosphonium bromide (264 mg, $0.69 \mathrm{mmol}$ ) in dry THF (5 mL) dropwise $n$ BuLi ( $2.5 \mathrm{M}$ in hexane, $0.3 \mathrm{~mL}, 0.79 \mathrm{mmol}$ ) at $-78{ }^{\circ} \mathrm{C}$ was added. The reaction mixture was warmed to $\mathrm{rt}$ over a period of $1 \mathrm{~h}$ before being cooled to $-78{ }^{\circ} \mathrm{C}$. To the obtained orange solution above crude aldehyde dissolved in THF ( $3 \mathrm{~mL}$ ) was added and the reaction mixture was left to warm to rt over $2 \mathrm{~h}$ before the addition of $\mathrm{H}_{2} \mathrm{O}$ $(10 \mathrm{~mL})$. The resulting suspension was extracted with EtOAc $(3 \times 10 \mathrm{~mL})$. The combined organic layers were washed with brine, dried over anhydrous $\mathrm{Na}_{2} \mathrm{SO}_{4}$ and concentrated under reduced pressure to afford olefin intermediate 10 as a colorless liquid which was used for the next reaction.

To a solution of above olefin intermediate 10 in methanol $(4 \mathrm{~mL})$ catalytic amount of palladium on carbon (10\%) was added and resulting reaction mixture was stirred under hydrogen atmosphere for $4 \mathrm{~h}$ at room temperature, at which point TLC indicated the completion of reaction. The reaction mixture was filtered through a pad of Celite, solvent was removed in vacuo and silica gel column chromatography (hexane/ EtOAc 10:1) furnished ethyl $(S)$-4-methyloctanoate (1a) $(73 \mathrm{mg}, 76 \%)$ as a colourless liquid. $[\alpha]_{\mathrm{D}}{ }^{25}+1.61\left(\mathrm{c} 1.0, \mathrm{CHCl}_{3}\right)$ $\left\{\right.$ lit. $^{4}[\alpha]_{\mathrm{D}}{ }^{20}+1.67$ (c 1.35, $\left.\left.\mathrm{CHCl}_{3}\right)\right\} ;$ IR $\left(\mathrm{CH}_{2} \mathrm{Cl}_{2}\right)$ v: 2957, 2946, 1735, 1478, 1268, $1215 \mathrm{~cm}^{-1} ;{ }^{1} \mathrm{H} \mathrm{NMR}(400 \mathrm{MHz}$, $\left.\mathrm{CDCl}_{3}\right) \delta: 4.12(\mathrm{~d}, J$ 7.32, $14.2 \mathrm{~Hz}, 2 \mathrm{H}), 2.33-2.26(\mathrm{~m}, 2 \mathrm{H}), 1.70-1.60(\mathrm{~m}, 1 \mathrm{H}), 1.47-1.41(\mathrm{~m}, 2 \mathrm{H}) 1.31-1.27(\mathrm{~m}, 5 \mathrm{H})$; $1.26(\mathrm{t}, J 6.88,3 \mathrm{H}) 1.15-1.09(\mathrm{~m}, 1 \mathrm{H}), 0.89(\mathrm{t}, J 6.88,3 \mathrm{H}), 0.88(\mathrm{~d}, J 6.40,3 \mathrm{H}) ;{ }^{13} \mathrm{C} \mathrm{NMR}\left(100 \mathrm{MHz}^{\mathrm{CDCl}} \mathrm{CD}_{3} \delta\right.$ : 174.2 , 60.2, 36.3, 32.4, 32.2, 31.9, 29.1, 22.9, 19.2, 14.2, 14.1. HRMS (ESI), $m / z$ calcd for $\mathrm{C}_{11} \mathrm{H}_{22} \mathrm{O}_{2} \mathrm{Na}[\mathrm{M}+\mathrm{Na}]^{+}$ 209.1512; found 209.1514.

(S)-4-methyloctanoic acid (2a). A mixture of ethyl (S)-4-methyloctanoate (1a) (50 mg, $0.27 \mathrm{mmol}$ ), LiOH (34 $\mathrm{mg}, 0.81 \mathrm{mmol})$, THF $(2 \mathrm{~mL})$ and water $(0.5 \mathrm{~mL})$ was stirred at room temperature for $6 \mathrm{~h}$. The organic solvent was removed under reduced pressure, and the residue obtained was then acidified to $p \mathrm{H} 5$ with $1 \mathrm{~N} \mathrm{HCl}$, and the reaction mixture was extracted with EtOAc $(3 \times 10 \mathrm{~mL})$. The combined organic layers were washed with brine, dried over anhydrous $\mathrm{Na}_{2} \mathrm{SO}_{4}$ and concentrated under reduced pressure. Silica gel column chromatography (hexane /EtOAc 9:1) afforded the target compound (S)-4-methyloctanoic acid (2a) (39 mg, $92 \%)$ as a colorless liquid. $[\alpha]_{D}{ }^{25}+1.46\left(c\right.$ 1.0, $\left.\mathrm{CHCl}_{3}\right) ;\left\{\right.$ lit. ${ }^{23}[\alpha]_{\mathrm{D}}{ }^{20}+1.5\left(c\right.$ 1.4, $\left.\left.\mathrm{CHCl}_{3}\right)\right\} . \mathrm{IR}\left(\mathrm{CH}_{2} \mathrm{Cl}_{2}\right)$ v: 3450, 3071, 2957, 2946, 1715, 1468, 1268, $1215 \mathrm{~cm}^{-1} ;{ }^{1} \mathrm{H}$ NMR (400 MHz, CDCl $) \delta: 2.42-2.31(\mathrm{~m}, 2 \mathrm{H}) ; 1.73-1.63(\mathrm{~m}, 1 \mathrm{H})$; 1.50-1.40 (m, 2H); 1.33-1.10 (m, 6H), 0.92-0.80 (m, 6H); $\left.{ }^{13} \mathrm{C} \mathrm{NMR} \mathrm{(100} \mathrm{MHz,} \mathrm{CDCl}_{3}\right) \delta: 180.3,36.3,32.3,31.8$, 31.6, 29.1, 22.9, 19.2, 14.1. HRMS (ESI), $m / z$ calcd for $\mathrm{C}_{9} \mathrm{H}_{18} \mathrm{O}_{2} \mathrm{Na}[\mathrm{M}+\mathrm{Na}]^{+}$181.1199; found 181.1219.

\section{Acknowledgements}

The authors acknowledge the research grant No. 02(0283)/16/EMR-II) facilitated by the Council for Scientific and Industrial Research (CSIR), New Delhi, India for the carrying out the study. R. Pandey thanks Thapar Institute of Engineering and Technology for the research associateship. We are thankful to Dr. Pradeep Kumar Tripathi, NCL Pune for HPLC data analysis.

\section{Supplementary Material}

Copies of ${ }^{1} \mathrm{H}$ and ${ }^{13} \mathrm{C}$ NMR spectra of compounds $\mathbf{9}, \mathbf{1 a}$ and $\mathbf{2 a}$ are available in the supplementary material file.

\section{References}


1. Dang, C. H.; Nguyen, C. H.; Im, C.; Nguyen, T. D. In Integrated Pest Management (IPM): Environmentally Sound Pest Management, Gill, H. Ed.; Intech: Rijeka, Croatia, 2016; p103.

2. Jacoba, T. K.; Bhumannavar, B. S. Trop. Pest Manage. 1991, 37, 80.

https://doi.org/10.1080/09670879109371542

3. Zelazny, B.; Alfiler, A. R. Environ. Entomol. 1986, 15, 84.

https://doi.org/10.1093/ee/15.1.84

4. Hallet, R. H.; Perez, A. L.; Gries, G.; Gries, R.; Pierce, H. D.; Yue, J.; Oehlschlager, A. C.; Gonzalez, L. M.; Borden, J. H. J. Chem. Ecol. 1995, 21, 1549.

https://doi.org/10.1007/BF02035152

5. Rochat, D.; Mohammadpoor, K.; Malosse, C.; Avand-Faghih, A.; Lettere, M.; Beauhaire, J.; Morin, J. P.; Pezier, A.; Renou, M.; Abdolahi, G. A. J. Chem. Ecol. 2004, 30, 387.

https://doi.org/10.1023/B:JOEC.0000017984.26917.52

6. Hoddle, M. S.; Hoddle, C. D. Pakistan Entomologist 2011, 33, 77.

7. Perez, A. L.; Hallett, R. H.; Gries, R.; Gries, G.; Oehlschlager, A. C.; Borden, J. H. J. Chem. Ecol. 1996, 22, 357.

https://doi.org/10.1007/BF02055104

8. Gunawardena, N. E.; Herath, H.M.W.K.B. J. Natn. Sci. Coun. Sri Lanka 1995, 23, 81.

9. Hallett, R. H.; Gries, G.; Gries, R.; Borden, J. H.; Czyzewska, E.; Oehlscnlager, A. C.; Pierce, Jr. H. D.; Angerilli, N. P. D.; Rauf, A. Naturwissenschaften 1993, 80, 328-331.

https://doi.org/10.1007/BF01141908

10. Ha, J. K.; Lindsay, R. C. J. Food Sci. 1991, 56, 1241-1250.

https://doi.org/10.1111/j.1365-2621.1991.tb04743.x

11. Ha, J. K.; Lindsay, R. C. Flav. Frag. 1991, 6, 81-85.

https://doi.org/10.1002/ffj.2730060112

12. Ha, J. K.; Lindsay, R. C. Lebensm. Wiss. Technol. 1990, 23, 433.

13. Dang, C-H.; Le, V.-D.; Nguyen, C-H.; Nguyen, T-D. Arkivoc, 2017, v, 187. https://doi.org/10.24820/ark.5550190.p010.271

14. Ragoussis, V.; Giannikopoulos, A.; Skoka, E.; Grivas, P. J. Agric. Food Chem. 2007, 55, 5050. https://doi.org/10.1021/if0704662

15. Sim, T. B.; Choi, J.; Yoon, N. M. Tetrahedron Lett. 1996, 37, 3137.

https://doi.org/10.1016/0040-4039(96)00510-2

16. Gries, G.; Gries, R.; Perez, A. L.; Oehlschlager, A. C.; Gonzalez, L. M.; Pierce, H. D.; Zebeyou, M.; Kouame, B. Z. Naturforsch. 1994, 49C, 363.

https://doi.org/10.1515/znc-1994-5-614

17. Sonnet, P. E.; Baillargeon, M. W. Lipids 1989, 24, 434.

https://doi.org/10.1007/BF02535152

18. Sonnet, P. E.; Gazzillo J. Org. Prep. Proced. Int. 1990, 22, 203.

https://doi.org/10.1080/00304949009458196

19. Karl, V.; Kaunzinger, A.; Gutser, J.; Steuer, P.; Angles-Angel, J.; Mosandl, A. Chirality 1994, 6, 420. https://doi.org/10.1002/chir.530060510

20. Hedenström, E.; Nguyen, B.-V.; Silks, L. A. Tetrahedron: Asymmetry 2002, 13, 835.

https://doi.org/10.1016/S0957-4166(02)00172-6 
21. Heinsman, N. W. J. T.; Valente, A. M.; Smienk, H. G. F.; Van der Padt, A.; Franssen, M. C. R.; Groot, A.; Van't Riet, K. Biotech. Bioeng. 2001, 76, 193. https://doi.org/10.1002/bit.10008

22. Litjens, M. J. J.; Straathof, A. J. J.; Jongejan, J. A.; Heijnen, J. J. Tetrahedron 1999, 55, 12411. https://doi.org/10.1016/S0040-4020(99)00724-3

23. Muñoz, L.; Bosch, M. P.; Rosell, G.; Guerrero, A. Tetrahedron: Asymmetry 2009, 20, 420. https://doi.org/10.1016/j.tetasy.2009.02.041

24. Tidwell, T. T.; Synthesis, 1990, 10, 857. https://doi.org/10.1055/s-1990-27036

25. Tidwell, T. T.; Org. React., 1990, 39, 297.

26. The enantiomeric excess of intermediate 8 was determined by in situ reduction with $\mathrm{NaBH}_{4}$ at $0{ }^{\circ} \mathrm{C}$ producing the corresponding diol. HPLC Chiralpak IB $(250 \times 4.6 \mathrm{~mm})$, petroleum ether:EtOH $(99: 1) \mathrm{v} / \mathrm{v}$, flow rate $1.0 \mathrm{ml} / \mathrm{min}, \lambda_{\max }=220 \mathrm{~nm},(2 R, 3 S)$ anti isomer $\mathrm{tr}=14.29 \mathrm{~min},(2 S, 3 R)$ anti isomer $\mathrm{t}_{\mathrm{r}}=15.89$ $\min ,(2 R, 3 R)$ and $(2 S, 3 S)$ syn isomers $t_{r}=18.35,19.88 \mathrm{~min}$.

27. Northrup, A. B.; Mangoin I. K.; MacMillan, D. W. C. Angew. Chem., Int. Ed., 2004, 43, 2152. https://doi.org/10.1002/anie.200453716

28. Smith III, Amos B.; Tomioka, T ; Risatti, C. A. ; Sperry, J. B.; Sfouggatakis, C. Org. Lett. 2008, 10, 4359. https://doi.org/10.1021/ol801792k 